\title{
Pedicle Subtraction Osteotomy in the Treatment of the Lumbar Spine Deformities
}

\author{
M.E.Abdelnaby, A.I.Bakr, M.A.Mohammed and A.D.Elsayed \\ Orthopedic Surgery Dept., Faculty of Medicine, Benha Univ., Benha, Egypt \\ E-Mail: amrelnagar2016@gmail.com
}

\begin{abstract}
Symptomatic altered sagittal disfigurement will be common clinched alongside grown-up patients introducing should spine surgeons. Settled sagittal lopsidedness camwood a chance to be characterized as a syndrome to which those tolerant will be unabated with remained erect without flexing the knees Also hips. Around a long-cassette parallel radiograph, this abnormality is normally watched Likewise An plumb transport from C7 that falls great in front of the L5-S1 circle. Settled sagittal lopsidedness ordinarily comes about starting with iatrogenic makes for example, hypolordotic fusions, pseudarthrosis, postlaminectomy, alternately kyphosis, What's more it might additionally come about starting with trauma, intrinsic abnormalities, or malady states (e. G. , ankylosing spondylitis) bring long combined regions about their spine that restrain their capability should adjust to their disfigurement through neck positioning Furthermore pelvic angulation. Pedicle subtraction osteotomies (PSOs) need been utilized within those medicine for various spinal states directing, including an altered sagittal imbalance, for example, such that degenerative scoliosis, idiopathic infection scoliosis, post-traumatic deformities, iatrogenic flatback syndrome, Furthermore ankylosing spondylitis. Those perfect gas implication for An straightforward PSO will be a immaculate sagittal imbalance, to a tolerant with a firm spine because of ankylosing spondylitis, postoperative level back, posttraumatic kyphosis, or immaculate arthrosis. Lumbar PSO may be shown in the medication about sagittal or sagittal Also coronal disfigurement of the spine over vicinity of hypolordosis, spine firmness and when the measure about essential revision of bring down appendage will be huge.
\end{abstract}

Keywords: Lumbar spine, Osteotomy, Lordosis, Pedicle subtraction osteotomy, Spine surgery.

\section{Introduction}

Medication of settled sagittal lopsidedness by obliges spinal osteotomy on recover worldwide spinal arrangement. Pedicle subtraction osteotomy (PSO) need formed as an progressively prevalent and capable strategy will right settled sagittal lopsidedness [1]. Pedicle subtraction osteotomy (PSO) might have been at first depicted Eventually Tom's perusing Thomasen to 1985 to patients for ankylosing spondylitis [2].

\section{Background}

The lumbar area comprises from claiming five vertebrae L1-5. It need An common lordotic bend What's more is a great deal bigger over size [3]. The lumbar vertebrae need aid overwhelming and large; wider transversely over anteroposteriorly, the most recent three vertebra figures are wedge shaped, their pedicles need aid short and overwhelming emerging from the upper and only the body, Along these lines that they have An shallow predominant score and a profound second rate one, same time the transverse techniques would long Furthermore thin, leveled anteroposteriorly, tasks sort of posteriorly, upwards and additionally laterally, for the accessory methodology which will be a little tubercle lying on the dorsal surface from claiming each one. Those spinous procedures would wide The point when seen laterally, limited Furthermore stretching under a extended limit when seen starting with over or The following [4]. Those lumbar bend starts during the working of the keep going thoracic vertebra, Furthermore finishes at the sacrovertebral point. It is that's only the tip of the iceberg denoted to females over over males; it. It will be raised anteriorly, and the convexity of the bring down three vertebrae continuously much more stupendous over that of the upper two[5]. The spine may be typically lordotic in the cervical Furthermore lumbar locales Furthermore kyphotic in the thoracic What's more lumbosacral districts. Together, these curves permit the occiput will be held On an adjusted design again those pelvis. Kyphosis, from those Greek statement kyphos,means "bowed alternately twisted." The point when utilized clinically, this term regularly intimates a expanded ebb and flow of the spine creating angulation for a over the top posterior convexity What's more foremost concavity. Expanded kyphosis is, by far, those the vast majority normal sagittal plane disfigurement. Furthermore, expanded kyphosis will be lesquerella tolerated clinically over expanded lordosis [6]. Various characterizations have been recommended to kyphosis through those A long time. A percentage characterizations are In view of pathologic finding. Different characterizations would dependent upon structural abnormalities 
watched ahead radiographs, for example, intrinsic deformities. Thoracic What's more thoracolumbar kyphosis need been connected with Numerous pathologic entities, including Scheuermann's disease, intrinsic vertebra malformation, disabled conditions, and posttraumatic What's more incendiary states. An especially Combative What's more risky structure from claiming kyphosis might create for patients for neurofibromatosis and osteogenesis blemished [7].

\section{Management}

Sagital lopsidedness will be a manifestation whose clinical offers differ for the underlying etiology. Securing those finding Also recognizing the make will be In this manner significant to guarantee that ideal medicine will be furnished [8]. Those clinical presentation would pain, deformity, practical inability Furthermore reduction for level gaze, all about which help lessening social freedom [9]. As opposed to youths for spinal deformity, who often introduce with worries of cosmesis or progression from claiming deformity, the practically commonpresentation for Grownups for spinal disfigurement will be torment Furthermore inability [10]. Those ache will be as a rule steady Furthermore throbbing inquality and happens at those level of the disfigurement or higher. Patients for an precise kyphotic disfigurement for $30^{\circ}$ or greatermay a chance to be toward a expanded hazard to constant once again ache. Patients might additionally encounter radicular pain, which may be regularly identified with degenerative transforms over alternately beneath the disfigured segment, prompting focal or foraminal spinal stenosis [11]. Those extent from claiming any disfigurement will be best for weight bearing. By thinking about the extent of a disfigurement on the upright Also supine $\mathrm{x}$-rays, an beginning appraisal of its adaptability camwood make made [12]. Using those Cobb technique, the general degree about kyphosis of the thoracic spine and in addition lumbar lordosis camwood make measured. The unrivaled What's more mediocre vertebra bodies, which would characterized Concerning illustration the most recent vertebra particular figure tilting under those kyphotic deformity, proximally What's more distally ought further bolstering make chose. An speck ought make put on the foremost What's more posterior corners of the upper wind plate of the unrivaled vertebra muscle to. A offering interfacing these two focuses is drawn. The same ought a chance to be finished to those bring down wind plate second rate vertebra body. The plot subtended by the peroxide blonde for these two lines determines those kyphotic disfigurement Fig $(1,2)$. It will be vital with select the same vertebra figures in looking at serial radiographs [13].

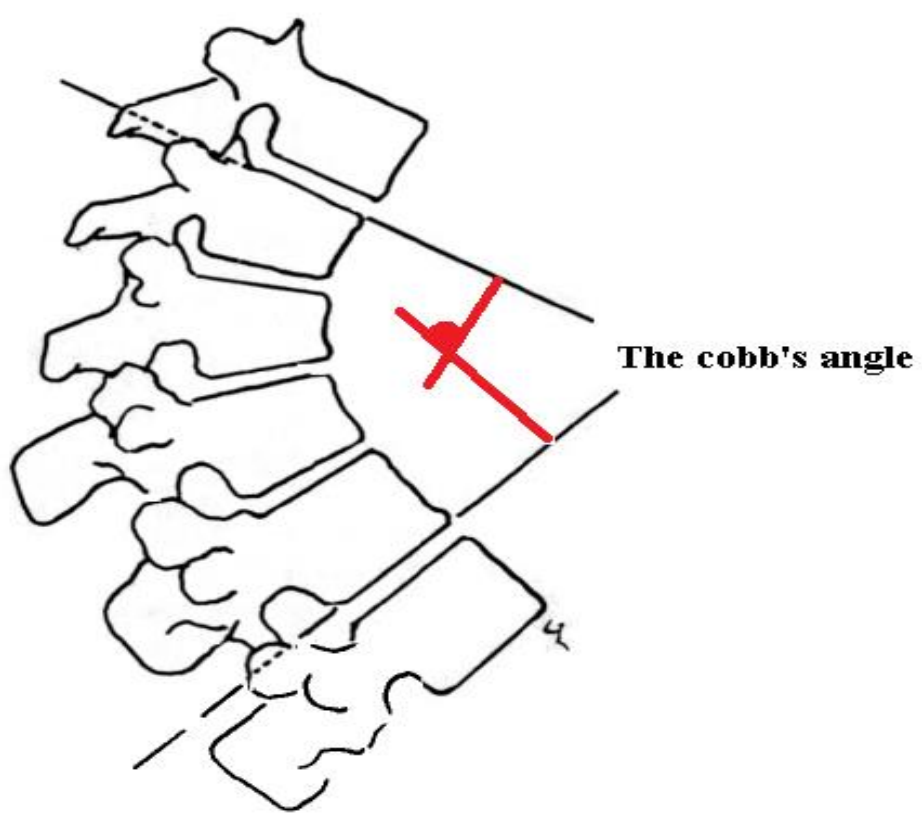

Fig (1) The cobb's angle (14). 

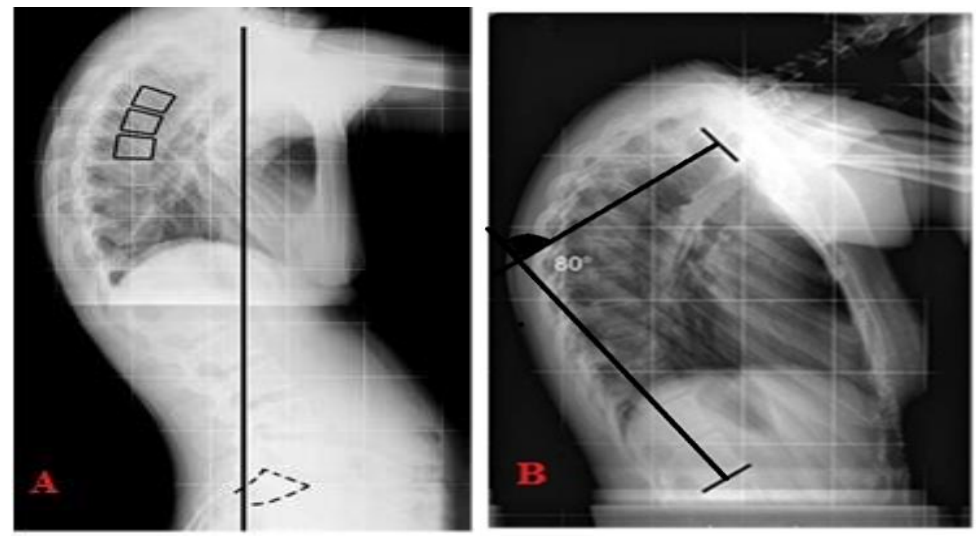

Fig (2) Lateral radiograph of a kyphotic spine with negative sagittal balance:A) vertical plumb line drawn from the middle of C7 passes posterior to the sacral end plate (dashed lines).B)Lateral radiograph of a kyphotic thoracic spine [15].

\section{The classification system}

Kyphosis exists Concerning illustration two unique types, round and angular: An) Postural round kyphosis:Round-back may be the The majority regular Furthermore best tolerated example from claiming kyphosis Also will be frequently ignored. There will be An largeradius smooth birch ebb and flow directing, including alarge amount of vertebrae. Those The majority normal area is those thoracic or thoraco-lumbar spine. The majority patients need no other abnormalities. Round kyphosis will be normally adaptable What's more reducible Throughout youth Be that as camwood try to an inflexible disfigurement Throughout youth [8].

precise kyphosis:Angular kyphosis is significantly All the more conspicuous, in any case from claiming its location, Similarly as a sharp point directing, including a little amount from claiming vertebrae disrupts those ordinary spinal shape. Precise kyphosis is lesquerella incessant Yet a greater amount genuine over round kyphosis. Progression might happen Throughout development Also prompt medication will be obliged. Precise kyphosis might be stable or unstable:i) stable precise kyphosis: the abnormality includes a little amount from claiming vertebrae exhibiting extreme deformities, and also the interceding disks, which might make pretty much complete contingent upon the result in. The capsules, ligaments, feature joints, Furthermore posterior and only the vertebra physique are soundness. Ii) flimsy precise kyphosis: might a chance to be brought on Eventually Tom's perusing trauma or intrinsic deformities. The danger about neurological trade off in this type for kyphosis will be for concern [8].

\section{Treatment of osteonecrosis includes}

\subsection{Non-surgical treatment}

Introductory medicine choices to kyphotic issues would nonsurgical. It primarily comprises of supporting Also physiotherapy Also need not transformed essentially for decades. Nonsurgical medicine might a chance to be utilized within a few patients for precise kyphosis, Concerning illustration An preliminary alternately What's more to surgical medicine [16]. It might make supplemented for non steroidal anti- incendiary regimens Furthermore muscle relaxers. Patients for more modest adaptable sagittal deformities would less averse will pick up easing starting with these non-operative measures over are the individuals patients with substantial extent settled deformities that resultin critical certain sagittal malalignment [17].

\subsection{Surgical treatment}

Spinal osteotomies for the Correction of severe sagittal deformity

Smith-Petersen osteotomy (SPO) might have been presented in the 1945 and from that point a few modifications, in the Ponte procedure, need been produced should treat hyperkyphotic deformities. SPO might have been primarily utilized within ankylising spondylitis $\mathrm{Be}$ that need been presented in the medicine of kyphoscoliosis and also blacks [18]. When a that's only the tip of the iceberg profound revision of the sagittal disfigurement may be required, pedicle substraction osteotomy alternately vertebral trench resection (VCR) might be essential [18].

An anatomic order for spinal osteotomies may be as of late suggested for 6 evaluations for admiration to those degree for bone resection Furthermore possibility destabilization impact of the surgical methodology [19]. 
Schwab anatomical classification of spinal osteotomies: Fig (3)

Review 1 halfway feature joint resection. Review 2 complete feature joint resection (both subpar Furthermore predominant facets resected).

Evaluation 3 pedicle and incomplete vertebra form resection (so-called PSO).

Evaluation 4 Pedicle, incomplete vertebra body What's more upper circle resection (socalled trans-discal PSO).

Review 5 finish resection from claiming vertebra constitution What's more both contiguous plates. Review 6 evacuation from claiming various contiguous vertebrae Also plates.

Evaluation 1 halfway feature joint resection. Review 2 complete feature joint resection (both mediocre Furthermore unrivaled facets resected).

Review 3 pedicle Furthermore fractional vertebra figure resection (so-called PSO).

Evaluation 4 Pedicle, incomplete vertebra muscle to Also upper circle resection (socalled trans-discal PSO).

Evaluation 5 finish resection for vertebra figure and both contiguous plates. Evaluation 6 evacuation for various contiguous vertebrae Also plates.
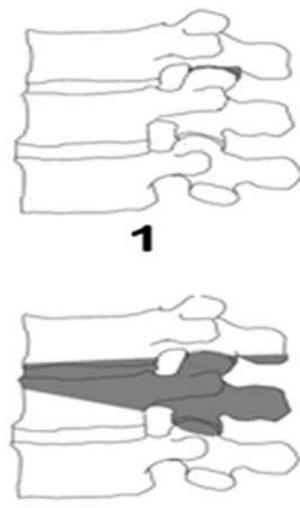

4

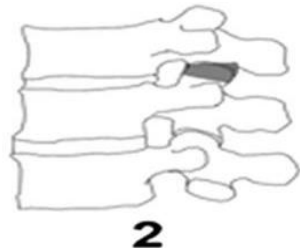

2

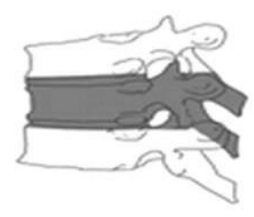

5

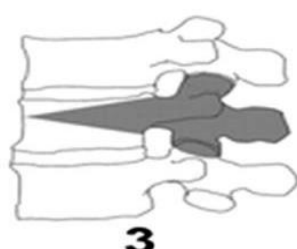

3

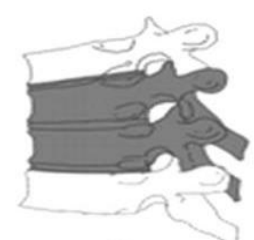

6

Fig (3) Osteotomy classification: grades 1 to 6 according to the anatomic resection.Grades 1 and 2 correspond to more or less extensive facet joint resection, grades 3 and 4 to PSO more or less associated with adjacent disk removal and grades 5 and 6 to vertebral column resection[20].

\section{Pedicle subtraction osteotomy}

\subsection{Objectives}

PSO has the advantages of obtaining a correction through three columns from the posterior approach without lengthening the anterior column, thereby maximizing the healing potential while avoiding stretching the major vessels and viscera anterior to the spine [18].

\subsection{Indications}

fixed sagittal imbalance, short angular deformities and severe global positive sagittal imbalance more than $6 \mathrm{~cm} \mathrm{[21].}$

Patients with a degenerative cause of the sagittal imbalance, psychiatric disease, diabetes, osteoporosis,substantial cardiopulmonary disease, and poor family or social support., [22].

\subsection{Surgical technique}

The system will be done with the tolerant lying inclined once a jackson outline or a open-frame spine radiolucent operating . An midline entry point through those zone on make exposed, develop the dismemberment in the midline utilizing An surgical tool or the electro-cautery blade through the shallow Also lumbodorsal fasciae of the tips of the spinous methods. Uncover subperiosteally those posterior components Eventually Tom's perusing reflecting those erector spinae muscle laterally of the tips of the transverse techniques distal on proximal, utilizing periosteal elevators. Repeatable the system until the fancied amount from claiming vertebrae are laid open [23]. The psoas muscle may be dismembered far starting with the parallel part of the vertebra constitution with a wipe adhere alternately periosteal elevator [16]. Pedicle screws are embedded under two or three segments over Also The following the pedicles tobe resected Similarly as they will be used to assistance secure Also settle those spine following those osteotomy [18]. Laminectomies and complete reciprocal facetectomies would afterward performed at the osteotomy level, those following venture is on decancellate those pedicles Also vertebra muscle to. The average divider of the pedicle is 
identified, and the thecal sac and the nerve root are withdrew for An Penfield retractor should recognize those posterior divider of the vertebra physique. Throughout those decancellation, it is essential will stay situated on making An wedge inside the vertebra figure with a wider resection posteriorly and a point of convergence anteriorly. When the posterior divider of the vertebra particular figure is dainty enough, An Woodson lift alternately An significant reverse-angled curette will be set the middle of those foremost dura and the posterior vertebra cortex What's more pushed anteriorly should make a greenstick crack of the posterior vertebra cortex [22]. Resection of the parallel dividers Furthermore vital waterway growth[24]. Conclusion of the osteotomy Furthermore last defiant [22]. The ventral angle of the vertebra form acts Similarly as An pivot Toward which the osteotomy site is shut in An way comparable with An shutting wedge osteotomy of the proximal and only the tibia. An transitory Pole is set to secure the spine former on osteomy Conclusion and the posterior decompression might have with a chance to be enlarged cephalad alternately caudad will uproot bone starting with the lamina over Furthermore beneath those osteotomy level to evade kinking of the dura Throughout osteomy Conclusion Fig (4) [16]. Disturbance of the ventral cortex of the vertebra physique will destabilize those spinal section [25].

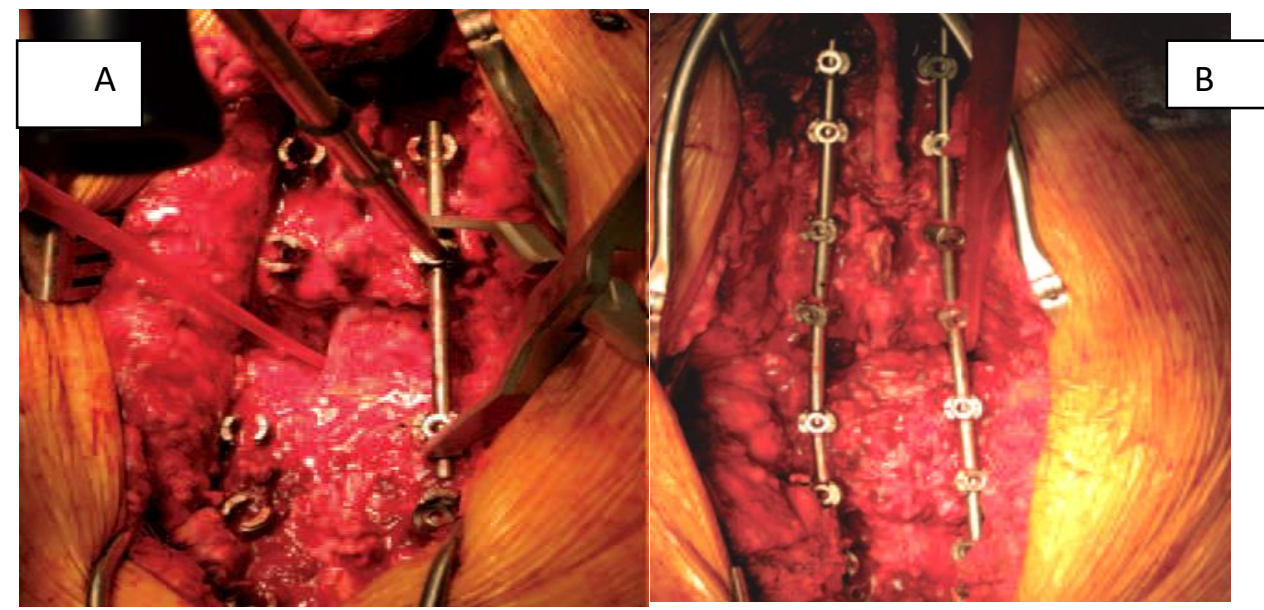

Fig (4) Clinical intraoperative photographs of pedicle subtraction osteotomy. Open osteotomy, dura exposed (A). Osteotomy closed and correction obtained (B) [21].

\subsection{Post operative care}

A 3 should 6 month span of thoracolumbosacralorthosis alternately lumbosacral orthosis with a thoracic development cushion which will be formed 12 days then afterward surgery might have been regularly endorsed for any tolerant for whom the PSO might have been backed best Eventually Tom's perusing segmental posterior defiant. Previously, whatever tolerant whose build might have been supplemented Toward an foremost section interbodyfusion, whichever no orthosis might have been suggested, or An strong lumbosacral bodice might have been worn to 1 should 3 months [26]. Importantly, it if be noted that patients were subjected will a decompensated standing posture for An in length time preoperatively Furthermore consequently would inclined with stay done An hunched posture considerably following surgical revision. So as with not return backto those preoperative habitual posture, patients would determinedly educated Throughout postoperative restoration to keep their middle Concerning illustration upright Likewise could be allowed At whatever point they ambulate [27]. Restoration may be A critical a piece of the recuperation methodology; a significant number about these patients would elderly Also come in for critical practical restrictions What's more it might take them a few months postoperatively in front of being autonomous. Their non-intrusive treatment prerequisites change generally Furthermore is best individualized In light of their assessment postoperatively Toward a non-intrusive treatment less group that is acquainted with this tolerant number [11].

\section{Conclusion}

Kyphosis will be isolating as stated by level about disfigurement under two sorts ,round kyphosis for example, postural round kyphosis Also precise kyphosis for example, such that 
precise gibbus disfigurement whitch need separate progression Also neurological impedance. Etiology about sagital lopsidedness maybeincludes atruma, congenital, developmentalanomalies, incendiary disease, degenerativedisease, infection, neuromuscular disease, spinal tumers Also iatrogenic. Kyphosis camwood make diagnosed by family history Furthermore presentation, physical examination incorporates neurological, radiological Also respiratory examination. Those objectives of surgery On patients for sagittal lopsidedness ought further bolstering be on reproduce typical physiological spinal alignment, streamline those possibilities for An great fusion, Furthermore decompress those neural components On there is symptomatic spinal trench stenosis. Pedicle subtraction osteotomy (pso)is a well-known surgical methodology in the oversaw economy about lumber spine disfigurement. It need been utilized with other posterior osteotomy systems for example, vertebral trench resection (VCR), What's more Smith-Peterson osteotomy (SPO) in the medication for symptomatic disfigurement in lumbar spine. PSO need the point from claiming being finished totally through An posterior approach without those necessity for an foremost technique. Intend pick up of lordosis then afterward PSO varies starting with 25 o on 40 o, it may be accordingly recommended The point when no less than 250 for restorative lordosis will be obliged. Those osteotomy is a angular resection that removes those posterior elements, pedicles, What's more and only those vertebra figure. Classically, the resection will be totally bony, In spite of the cephalad plate space might additionally make resected. The pedicle subtraction osteotomy will be An a greater amount capable apparatus that shuts anteriorly What's more revision may be attained through at three columns of the spine. This considers revision Previously, both those sagittal and the coronal plane. Done addition, the spine may be not lengthened, thereby avoiding the vascular What's more abdominal difficulties connected with development osteotomies. PSO yields hard relation anteriorly and posteriorly, giving work to more amazing soundness Furthermore a higher combination rate. PSO is a actually requesting system requiring a impeccable understanding of the standards about sagittal parity. It also obliges an aggregate dominance of intracanal spinal surgery Also a impeccable appreciation of spinal biomechanics Furthermore standards from claiming spinal defiant. PSO need satisfactory rate of intraoperative Also postoperative difficulties. Neurological deficits that go with the system would accepted should be those aftereffect of a mix of subluxation, lingering dorsal impingement, and dural buckling. Notwithstanding those generous muddling rate, a acceptable Conclusion is achievable Gave An careful, systematic, and actually wellexecuted surgery will be performed.

\section{References}

[1] S. Peter Rose, H. Keith Bridwell, G. Lawrence Lenke, A.Geoffrey Cronen, S. Daniel Mulconrey, M.Jacob Buchowski, and J.Youngjung Kim ,Role of Pelvic Incidence, Thoracic Kyphosis, and Patient Factors on Sagittal Plane Correction Following Pedicle Subtraction Osteotomy. Spine, Vol. 34, PP.. 785-791,2009.

[2] Cedric Barrey , Gilles Perrin, Frederic Michel , Jean-Marc Vital, Ibrahim Obeid ,Pedicle subtraction osteotomy in the lumbar spine: indications, technical aspects, results and complications. Eur $\mathbf{J}$ Orthop Surg Traumatol, Vol. 30, PP.. 775-781,2014.

[3] W .George, II .Wood, spinal anatomy and surgicalapproaches: The spine. In: Canale ST, Beaty JH(Eds), Campbell's operative orthopaedics, Elsevier mosby.12th edition; 2: part XI chapter,Vol. 37, PP.. 1524$59,2013$.

[4] N. Bogduk and R. Engel, The menisci of the lumbar zygoapophyseal joints: A review of their anatomy and clinical significnce. Spine; Vol.9, PP..454,1984.

[5] HA. Keim , The Adolescent Spine. 2nd edition. Springer-Verlag, New York, Vol.7, PP..458,1987.

[6] R .Lugo, J N .Graue, J M .Beiner, Kyphosis of the Cervical, Thoracic,and Lumbar Spine In Fisicaro MD. spine core knowledge. Chapter Vol.10, PP.. P 125135,2005.

[7] RT. Holt Dopf ,CA. Isaza , Adult Kyphosis in the adult spine, principles and practice.2nd edition. Pp, Vol.1537, PP..15-78,1997.

[8] L.Miladi , Round and angular kyphosis in paediatric patients Orthop Traumatol Surg Res ;Vol.99(1 Suppl), PP..S140-9,2013.

[9] P .Roussouly, C. Nnadi , Sagittal plane deformity: an overview of interpretation and management. Eur Spine J. Nov;Vol.19(11), PP..1824-36,2010.

[10] JS .Smith, CI. Shaffrey, Fu. K-MG, JK .Scheer, S. Bess, V. Lafage, Clinical and Radiographic Evaluation of the Adult Spinal Deformity Patient. Neurosurg Clin N Am ,Vol.24(2), PP.. 143-156,2013.

[11] KM. Kebaish , Spinal Sagittal Plane Deformities: Etiology, Evaluation, and 
Management. Semin Spine Surg,Vol. 21(1), PP..41-48,2009.

[12] PD .Angevine, MG. Kaiser, Radiographic measurement techniques: the thoraco lumbar spinal deformity evaluation \& treatment spinal deformity. Neurosurgery; Vol.63 (3), PP.. A40-44,2008.

[13] AD .Sharan, W. Lavelle, TJ .Errico , Scheuermann's Kyphosis: Pediatric deformity. In: Errico TJ, Lonner BS, Moulton AW (Eds): Surgical management of spine deformities, Saunders Elsevier,Vol. 1st edition, Section2: chapter8, PP..119-124,2009.

[14] TR .Kuklo , Radiographic Evaluation of Spinal Deformity. Neurosurg Clin N Am;Vol. 18, PP.. 215-222,2007.

[15] K .B .Wood, R. Melikian, F .Villamil, Adult Scheuermann's Kyphosis: Evaluation, Management, and New Developments. J Am Acad Orthop Surg; Vol.20, PP..113-121,2012.

[16] RF .Heary, CI .Shaffrey, MY .Wang, PV .Mummaneni , Pedicle subtraction osteotomy:Thoracolumbar spinal deformity evaluation and treatment. Neurosurgery, Vol. 63(3), PP..A171A176,2008.

[17] E. Angel and F .Michael, Thoracic and Thoracolumbar Kyphosis in Adults. Spine ,Vol. 31, PP. 19, S161-S170,2006.

[18] KT. Kim, KJ .Park and JH .Lee , Osteotomy of the Spine to Correct the Spinal Deformity, Asian Spine Journal ,Vol.3(2), PP..113-23,2009.

[19] C .Barrey, G .Perrin, F .Michel, J-M. Vital, I. Obeid, Pedicle subtraction osteotomy in the lumbar spine: indications,technical aspects, results and complications, Eur J Orthop Surg Traumatol ,Vol.24(4) Suppl 1, PP..S2130,2014.
[20] F .Schwab, B .Blondel, E .Chay, J. Demakakos, L .Lenke, P .Tropiano, , The comprehensive anatomical spinal osteotomy classification. Neurosurgery;Vol. 74(1), PP..11220,2014.

[21] PF. Bergin, JR. O’Brien, LE. Matteini, WD. Yu, KM .Kebaish ,The use of spinal osteotomy in the treatment of spinal deformity. Orthopedics;Vol.33(8), PP..586-94,2010.

[22] KH .Bridwell, SJ .Lewis, A .Rinella, MD, LG. Lenke, Pedicle Subtraction Osteotomy for the Treatment of Fixed Sagittal Imbalance JBJS Am;Vol.85, PP..454-63,2003.

[23] N .Boos, C .Affolter, M .Merkle, FJ. Ruehli , Surgical Approaches. In: Boos N, Aebi M: Spinal disorders: fundamental of diagnosis and treatment, Springer-Verlag Berlin Heidelberg. Section,Vol. 13, PP.. 345-356,2008.

[24] V. Lafage, F .Schwab, S. Vira, R. Hart, D .Burton, JS .Smith, Does vertebral level of pedicle subtraction osteotomy correlate with degree of spinopelvic parameter correction? J Neurosurg Spine;Vol.14(2), PP..184-91,2011.

[25] B .Gill, A .Levin, T .Burd, and M. Longley, Corrective osteotomies in spine surgery. JBJ Surg Am ;Vol.90, PP..25092520,2008.

[26] SJ. Hyun, SC. Rhim , Clinical Outcomes and Complications after Pedicle Subtraction Osteotomy for Fixed Sagittal Imbalance Patients : A Long-Term Follow-Up Data J Korean NeurosurgSoc ,Vol.47, PP.. 95-101,2010.

[27] M.Kanayama , Sagittal plane correction in pedicle subtraction osteotomy using the Xia 3 SUK Direct Vertebral Rotation System J Neurosurg Spine,Vol. 19, PP..507-514,2013. 